evaluate a nurse-led sleep clinic to look at outcomes in terms of melatonin prescribing.

Methods All new referrals attending a nurse-led sleep clinic were examined from June 2016 to March 2017. Patients/ parents attending the clinic were given an individualised sleep programme to implement with their child at home, with ongoing follow-up support. Families received an average of 3 face-to-face clinic visits and 3 follow-up telephone calls from first visit to discharge. Retrospective data was gathered from clinic records [Clinical Audit approval number CA1309].

Results 69 patients aged 1-17 years (31 males) were analysed. The primary complaint was 'problem with sleep initiation and maintenance' (81\%), 'problem with sleep initiation' (13\%) and 'problem with sleep maintenance' (6\%). $84 \%$ of patients had medical co-morbidities; $54 \%$ of which were neuro-disability, the commonest being ASD and/or ADHD. 40/69 patients were successfully discharged from the clinic during the evaluation period. $65 \%$ were discharged without melatonin $(23 \%$ with neurodisability; $42 \%$ without neurodisability), of which $35 \%$ were weaned off melatonin and $30 \%$ avoided melatonin prescriptions. $12 \%$ felt that the sleep intervention had been successful but still required melatonin, $15 \%$ were referred to medical/psychology clinics, and $8 \%$ were non-compliant with the behavioural sleep programme and were discharged still taking melatonin.
Discussion In this cohort of paediatric insomnia patients, a brief but intensive behavioural programme with support from a specialist sleep nurse was effective in resolving sleep difficulties and reducing melatonin usage.

We recommend that standardised sleep support from trained practitioners should be available prior to prescribing melatonin for children with sleep difficulties. This approach is not only beneficial in effectively resolving sleep problems but is cost-effective when compared with melatonin prescribing.

\section{P014 PAEDIATRIC SLEEP DIARIES AND ACTIGRAPHY- OPINIONS OF THE STAKEHOLDERS}

${ }^{1}$ Ruth Kingshott*, ${ }^{1}$ Lowri Thomas, ${ }^{1}$ Heather Elphick, ${ }^{2,3}$ Abigail Needham, ${ }^{3}$ Angel JimenezAranda, ${ }^{4}$ Hajar Razaghi. 'The Sleep Unit, Sheffield Children's NHS Foundation Trust, Sheffield, UK; ${ }^{2}$ NIHR Children and Young People MedTech Cooperative, Sheffield Children's NHS Foundation Trust, Sheffield, UKi ${ }^{3}$ NIHR Devices for Dignity MedTech Cooperative, Sheffield Teaching Hospitals NHS Foundation Trust, Sheffield, UK; ${ }^{4}$ Dept of Engineering and Mathematics, Sheffield Hallam University, Sheffield, UK

\subsection{6/bmjresp-2019-bssconf.14}

Introduction Paper sleep diaries and actigraphy are useful tools in Sleep Medicine to evaluate sleep wake patterns in the home environment over the course of 7-14 days. In our service, the demand for actigraphy far outweighs the

\begin{tabular}{|c|c|c|}
\hline Opinions on: & Families $(n=20)$ & Health Professionals $(n=27)$ \\
\hline Sleep Diaries & $\begin{array}{l}\text { Confusing to complete } \\
\text { Complicated start times of each } \\
\text { day } \\
\text { Hard to estimate sleep times } \\
\text { Is all the information collected } \\
\text { necessary? } \\
\text { Would prefer electronic version } \\
\text { Useful to see sleep/wake } \\
\text { patterns }\end{array}$ & $\begin{array}{l}\text { Missing data } \\
\text { Mismatch with actigraphy } \\
\text { Incorrectly completed } \\
\text { Useful for sleep perception mismatch } \\
\text { Useful for behavioural sleep strategies }\end{array}$ \\
\hline Actigraphy & $\begin{array}{l}\text { Embarrassing especially at school } \\
\text { Uncomfortable } \\
\text { Refusal to wear at school }\end{array}$ & $\begin{array}{l}\text { Time consuming resource-wise } \\
\text { Variability in actigraphy used and } \\
\text { outcomes recorded } \\
\text { Useful for daytime napping } \\
\text { Useful for circadian rhythm shifts } \\
\text { Some centres autoscoring actigraphy, } \\
\text { some manual } \\
\text { Would like to do actigraphy but no } \\
\text { current resources }\end{array}$ \\
\hline
\end{tabular}


available resources. As such the team are investigating using an electronic sleep diary, integrating with actigraphy and simplifying the whole process. The first stage of this process was to ask the stakeholders their opinions of sleep diaries and actigraphy.

Methods Stakeholders were asked about sleep diaries and actigraphy considering all aspects of the process from when to request a referral and organising collection, completing a diary and wearing actigraphy, through to analysing and interpreting results. Questions asked were appropriate to the different stakeholder groups involved. Families and local hospital staff were interviewed and British Paediatric Sleep Society (BPSA) members and families undergoing actigraphy were sent appropriate brief questionnaires relevant to their part of the pathway [Service evaluation SE1347].

Results 47 stakeholders provided feedback. Interviews were conducted with 14 staff, 9 parents and 3 young people. Additional questionnaires were completed by 8 families undergoing actigraphy and 13 BPSA responders. A summary of the most common responses is shown in table 1 . Most institutions were issuing sleep diaries and actigraphy to specific patient groups due to limited resources.

Discussion This stakeholder engagement provides useful information to improve the use of sleep diaries and actigraphy within our paediatric clinical setting. If the process can be simplified then more sleep diary and actigraphy usage can occur at the triage stage of the sleep referral process and prevent unnecessary sleep studies, benefitting both families and limited resources. Feedback received confirms the current solution for paediatric sleep diaries and actigraphy is not ideal and there is a need to identify new approaches to increase usability, acceptability and stakeholder's satisfaction.

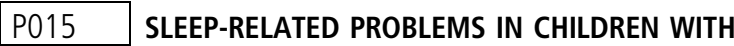 OSTEOGENESIS IMPERFECTA}

Claire Hill, Kieran Murphy, Ruth Kingshott*, Nicki Barker. Sheffield Children's NHS Foundation Trust, Sheffield Children's Hospital, Western Bank, Sheffield, UK

\subsection{6/bmjresp-2019-bssconf.15}

Introduction Osteogenesis Imperfecta (OI) is a genetic disorder affecting 1 in 10,000 births with a wide variability in phenotypes. Clinical manifestations include; recurrent fractures, bone pain, varying degrees of short stature and deformity, scoliosis, kyphosis, and respiratory failure in the severest types.
Sleep disorders are often under-acknowledged and are frequently more problematic in children with chronic illnesses. Children with OI are likely to complain of poor sleep quality due to pain, night sweats, structural changes in the chest and spine restricting the lungs, and soft tissues changes leading to decreased muscle tone, which may be linked to obstructive sleep apnoea.

The aim of the current project was to examine whether sleep-related problems are a significant issue to patients with OI at Sheffield Children's Hospital.

Methods A convenience sample of children with OI and their carers completed questionnaires designed by the project team to capture sleep and respiratory-related problems [service evaluation SE1090].

Results 55 patients (26 female; mean age 12.77 yrs; range 3.117.3) and carers completed the questionnaires during routine admission or clinic appointment. Participants were classified by OI type; 32-mild, 13-moderate, 10-severe.

$67 \%$ reported difficulty in getting off to sleep. $36 \%$ of participants reported waking in the night, with discomfort $(44 \%)$ and feeling too hot $(36 \%)$ being the most common causes. Frequency of night time waking ranged from $0-4$ times a night. $27 \%$ of participants reported snoring.

Discussion This service evaluation highlighted that OI patients are reporting sleep-related issues and further focus on sleep in the clinical history may be of importance. A pilot study examining the feasibility of polysomnography and sleep-related questionnaires in children with OI is currently underway to further research sleep in this cohort.

\section{P016 USING NON-INVASIVE THERMAL IMAGING FOR APNOEA DETECTION}

${ }^{1}$ Usman Muhammad, ${ }^{1}$ Ruth Evans, ${ }^{1}$ Reza Saatchi, ${ }^{2}$ Ruth Kingshott* ${ }^{*}{ }^{2}$ Heather Elphick. ${ }^{1}$ Materials and Engineering Research Institute, Sheffield Hallam University, Sheffield, UK; ${ }^{2}$ Sheffield Children's NHS Foundation Trust, Sheffield, UK

\subsection{6/bmjresp-2019-bssconf.16}

Introduction The current gold standard sensors to measure airflow in apnoea and hypopnoea detection are the oronasal thermal airflow sensor and the nasal pressure transducer, respectively. ${ }^{1}$ Due to the contact nature of these sensors in the nasal region, they are poorly tolerated by children. In a recent audit, we found that $50 \%$ of children refused the nasal pressure sensor due to its invasiveness, and of those that

\begin{tabular}{|c|c|c|c|c|c|c|}
\hline \multirow{2}{*}{$\boldsymbol{N}$} & \multicolumn{3}{|c|}{ Males } & \multicolumn{3}{c|}{ Females } \\
\cline { 2 - 7 } & $\begin{array}{c}\text { Elementary } \\
\text { (Parent- } \\
\text { report) }\end{array}$ & $\begin{array}{c}\text { Intermediate } \\
\text { (Self-report) }\end{array}$ & $\begin{array}{c}\text { Secondary } \\
\text { (Self- } \\
\text { report) }\end{array}$ & $\begin{array}{c}\text { Elementary } \\
\text { (Parent- } \\
\text { report) }\end{array}$ & $\begin{array}{c}\text { Intermediate } \\
\text { (Self-report) }\end{array}$ & $\begin{array}{c}\text { Secondary } \\
\text { (Self- } \\
\text { report) }\end{array}$ \\
\cline { 2 - 7 } & 50 & 39 & 50 & 50 & 50 & 50 \\
\hline Mean age & 10 & 14 & 16 & 10 & 14 & 16 \\
\hline Mean score CSHQ & 48 & 53 & 48 & 49 & 55 & 54 \\
\hline $\begin{array}{c}\text { Percentage of sleep } \\
\text { difficulties }\end{array}$ & $86 \%$ & $95 \%$ & $86 \%$ & $86 \%$ & $100 \%$ & $100 \%$ \\
Score of 41 or above & & & & & & \\
\hline Average sleep time & $9 \mathrm{pm}$ & $11 \mathrm{pm}$ & $11 \mathrm{pm}$ & $10 \mathrm{pm}$ & $11 \mathrm{pm}$ & $11 \mathrm{pm}$ \\
\hline Average wakeup time & $6 \mathrm{am}$ & $6 \mathrm{am}$ & $6 \mathrm{am}$ & $5 \mathrm{am}$ & $5 \mathrm{am}$ & $5 \mathrm{am}$ \\
\hline Average sleep duration & 9 & 7 & 7 & 7 & 6 & 6 \\
\hline
\end{tabular}

Abstract P016 Figure 1 Sample characteristics and the CSHQ scores 